\title{
Low-Cost High Power-Density Electronic Ballast for Automotive HID Lamp
}

\author{
Alberto Reatti
}

\begin{abstract}
A low-cost high-efficiency high power-density electronic ballast for $35 \mathrm{~W}$ automotive high intensity discharge (HID) lamps is presented along with the results of theoretical computations and experimental tests. The ballast circuits is based on a 100 kHz resonant inverter, a half-wave rectifier and a $400 \mathrm{~Hz}$ operated square-wave inverter. The converter operates at zero turn on losses, nearly zero turn off losses, and at a reduced electromagnetic interference level. The ballast circuit is designed to prevent inappropriate operations due to the acoustic resonances. The lamp voltage waveform has limited $d v / d t$ and no dc component contributing to a long operating life of the lamp.

A breadboard of the electronic ballast was designed and experimentally tested on a $35 \mathrm{~W}$ lamp, for a dc input voltage ranging from $9 \mathrm{~V}$ to $16 \mathrm{~V}$.

The electronic ballast performs all the features required to turn-on, warm-up and drive at the steady state a 35 W HID lamp and operates at a maximum steady state efficiency $\eta=84 \%$.
\end{abstract}

Index Terms-HID, resonant inverter, waveform, ZVS.

\section{INTRODUCTION}

A UTOMOTIVE high intensity discharge (HID) lamps are $35 \mathrm{~W}$ high-pressure Xenon gas discharge lamps, designed for a horizontal position operation at a steady state rms voltage ranging from $70 \mathrm{~V}$ to $100 \mathrm{~V}$. These lamps offer higher lighting emissions than $50 \mathrm{~W}$ halogen lamps and have an expected 5000 $\mathrm{h}$ operating life which is achieved if the voltage across the lamp terminals has a symmetrical waveform with zero dc component and is negative [1]-[4]. HID lamp steady-state operation at frequencies higher than some kilohertz suffers from the effect of the "acoustic resonance" which causes unstable arc, flicker, arc extinguishing, and lamp destruction. Therefore, it is crucial to drive these lamps with proper current and/or voltage waveforms at a proper frequency. Manufacturers recommend to operate the lamps at frequencies lower than $8-9 \mathrm{kHz}$, and they give no information neither on a lamp behavior at higher frequencies nor on start-up transient behavior. Therefore, determination of appropriate design specifications of the ballast circuit requires an accurate analysis of the specific lamp to be supplied. Several methods to predict and prevent the acoustic resonance and several electronic ballast circuits have been presented [5]-[16]. However, these methods and circuits refer to $70 \mathrm{~W}$ and/or $150 \mathrm{~W}$ HID lamps for lighting systems and cannot be directly applied to automotive lamps. The automotive lamp ballast proposed in [17] results in a large number of components and requires large

Manuscript received November 25, 1998; revised August 6, 1999. Recommended by Associate Editor, L. Nerone.

The author is with the Department of Electronic Engineering, University of Florence, Florence 50139, Italy.

Publisher Item Identifier S 0885-8993(00)02342-5. volume inductors and transformers because the entire circuit is operated at a $400 \mathrm{~Hz}$ frequency. The circuit described in [18] results in a small volume because is operated in the megahertz range. A potential limitation in practical application of this circuit is that the high frequency operation of a HID lamp results in a high radiated electromagnetic noise level.

The purpose of this paper is to present a high power-density and low-cost ballast circuit suitable for automotive applications along with the ballast circuit design specifications derived by means of theoretical computations and experimental tests.

The ballast circuit is constituted of a dc-to-ac class E resonant inverter operated in the hundred kilohertz range, a peak rectifier operated at the same frequency, and a square-wave inverter supplying the lamp by a $400 \mathrm{~Hz}$ square-wave voltage. The resonant inverter increases car battery voltage (in the $9 \mathrm{~V}$ to $16 \mathrm{~V}$ range) to higher voltage levels appropriate for lamp operation and presents the following advantages with respect to conventional PWM boost converters used in automotive applications.

1) Class $E$ and class $D$ resonant inverters result in a very high efficiency operation dc-ac converters [19]-[23]. Moreover, class E Zero-Voltage-Switching (ZVS) inverters are single switch resonant voltage boosters [24]-[27].

2) Class E inverters loaded with series-parallel and/or parallel resonant circuits are inherently protected against no load operations [23]-[27].

3) The current waveforms in these inverters are nearly sinusoidal resulting in transformers and inductors low winding and core losses and core loop full utilization.

4) The transformer leakage inductance is utilized as series inductance in the resonant circuit [13], [18], [25] and [28] and does not adversely affect the converter operation.

Main limitations of the single switch class E ZVS inverters are high rms currents and a high reverse voltage across the switch. However, the $400 \mathrm{~mA}$ steady-state lamp current makes the current in the inverter to be relatively low so that conduction losses keep low. Moreover, an input voltage ranging form $9 \mathrm{~V}$ to 16 $\mathrm{V}$ allows for a low reverse-voltage low ON-resistance device to be used as a controlled switch in the inverter. The voltage booster operating frequency has been limited to $100 \mathrm{kHz}$ to utilize low-cost easily available ferrite cores for inductors and transformers. The voltage booster supplies a rectifier circuit, which prevents any dc current component to flow through the lamp bulb. A $400 \mathrm{~Hz}$ inverter allows for a lamp operation at low frequency square-wave voltage with limited $d v / d t$ at polarity transitions. A single stage converter based on a Class D resonant inverter could be used to drive the lamp. However, the entire converter should be operated at frequency lower than some 
kilohertz resulting in large size and heavy weight or at frequencies above $1 \mathrm{MHz}$ requiring special components to be used.

The significance of the paper is that the ballast operates at a high efficiency, and at a low radiated electromagnetic interference, is constituted by a low number of standard components, has a light weight, a small size, a high power-density, and allows for a long life lamp operation. A maximum efficiency $\eta=$ $84 \%$ was achieved at steady state operation for the entire ballast circuit.

\section{AUtOMOTIVE HID LAMP OPERATION AND DERIVATION OF BALLAST DESIGN SPECIFICATIONS}

Fig. 1 shows the lamp voltage, current, power and equivalent resistance during the break-over, take-over, warm-up, and steady state operation.

\section{A. Transient Operation (Break-Over and Warm-Up)}

At the transient very beginning the lamp operates like on open circuit, and can be safely turned on if a $25-30 \mathrm{kV}$ voltage (lamp break-over) is supplied for a few tens of microseconds. Then, the lamp bulb requires a take-over current to sustain the arc for some milliseconds before the ballast supplies energy to the lamp. The arc discharge is actually achieved by delivering to the bulb the energy stored in a capacitor across the lamp electrodes. During the take-over, the lamp equivalent resistance decreases from high values to a few tens of ohms. After the arc has been produced inside the bulb, the lamp requires a high current warm-up for a few seconds. This time must be very short in automotive applications because the lamp operates at a reduced lighting flux until warm-up is over. Experimental tests performed demonstrated that a cold and new $35 \mathrm{~W}$ Automotive HID lamp requires a 2 A rms current and, approximately, a 70 $\mathrm{W}$ power to achieve a few seconds warm-up time.

\section{B. Steady State Operation}

Manufactures recommend a $85 \pm 20 \% \mathrm{~V}$ rms voltage steady state operation with a lamp current $I_{L}=400 \mathrm{~mA}$ current. This roughly results in a lamp equivalent resistance $R_{L}=200 \Omega$ as shown in Fig. 1. The plots of lamp current $I_{L}$ versus the voltage across the lamp electrodes $V_{L}$, for new and a 2000 hours operated lamps are shown in Fig. 2.

Experimental tests have also demonstrated that an equivalent inductance $L_{I}=280 \mu \mathrm{H}$ models the lamp ignitron at the steady-state operation (the ignitron transformer secondary winding mainly contributes to this inductance). Consequently, the steady-state equivalent circuit of the lamp along its ignitron is constituted by a series combination of the lamp resistance and ignitron circuit inductance. The reactance associated to the ignitron inductance $L_{I}=280 \mu \mathrm{H}$ is negligible with respect to the lamp resistance up to $\approx 10 \mathrm{kHz}$.

The acoustic resonance frequencies in a HID lamp depend on the bulb shape, dimensions, gas pressure etc. The main resonance frequencies along the three dimensional space axis of a cylindrical bulb are given by [5]

$$
f_{L}=\frac{C}{2 L} \quad f_{R}=\frac{3.83 C}{2 \pi R} ; \quad \frac{1.84 C}{2 \pi R}
$$

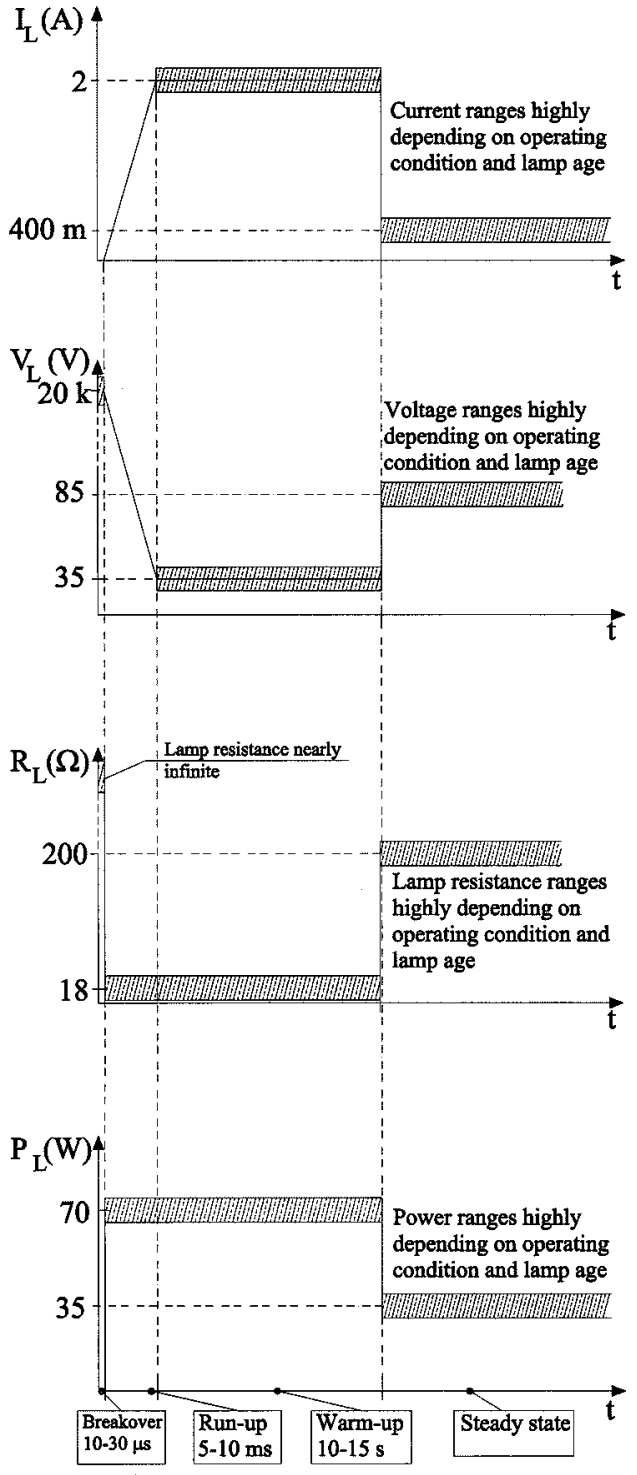

Fig. 1. Electric parameters of a new $35 \mathrm{~W}$, automotive, HID lamp at the break-over, run-up, warm-up, and steady-state operations. (a) Lamp current $i_{L}$. (b) Lamp voltage $v_{L}$. (c) Lamp equivalent resistance $R_{L}$. (d) Lamp power $P_{L}$.

where: $f_{L}, f_{R}, f_{A}$ are the resonance frequencies along the longitudinal, radial, and azimuth bulb directions, respectively, $C$ is the sound speed in the gas filling the bulb, $L$ is the electric arc length, and $R$ is the cylindrical bulb height. Automotive HID lamps have a cylindrical bulb with a radius $R=1.2 \pm 0.2 \mathrm{~mm}$, an arc length $L=4.2 \pm 0.45 \mathrm{~mm}$, resulting in a ratio $L / R=$ 2. By assuming that the sound speed in a HID Xenon lamp is $C=560 \mathrm{~m} / \mathrm{s}$ [5], the three main resonance frequencies has been calculated as $f_{L}=66 \mathrm{kHz}, f_{R}=284 \mathrm{kHz}$, and $f_{A}=$ $136 \mathrm{kHz}$. Actually, HID lamps show more resonance frequencies than those given by (1). The lamp current resulting in unstable operation and other resonance frequencies are determined according to theoretical computations given in [5] as shown in Fig. 3(a). The lamp frequency behavior shown in Fig. 3(b) has been experimentally determined by laboratory measurements. Plots of Fig. 3 show that in a frequencies range from $10 \mathrm{kHz}$ to 
$1 \mathrm{MHz}$ there are no frequency sub-ranges large enough to allow for a safe stable lamp operation inside the $10 \mathrm{kHz}-1 \mathrm{MHz}$ range.

Electronic circuits operated in the megahertz range produce a high level radiated electromagnetic noise, which is not recommendable in automotive applications. Moreover, the ignitron reactance at $1 \mathrm{MHz}$ operation is larger than $1.8 \mathrm{k} \Omega$ and the resulting voltage drop across the ignitron circuit would be much higher than the lamp operating voltage. An electronic ballast supplying the lamp with a steady state $300-500 \mathrm{~Hz}$ nearly square-wave current/voltage results in a low component number and a low-cost circuit allowing for a stable and long life lamp operation.

\section{Ballast Design Specifications}

Results of theoretical calculations and experimental tests performed on automotive HID lamps allowed the ballast design specifications to be derived as follows.

1) Steady-State Specifications:

1) Input voltage range: $9 \div 16 \mathrm{~V} \mathrm{dc}$.

2) Nominal output power: $35 \pm 3 \mathrm{~W}$;

3) Nominal output current: $400 \mathrm{~mA} \mathrm{rms}$;

4) Nominal output voltage: $V_{L}=85 \mathrm{~V} \mathrm{rms},\left(V_{L \min }=68 \mathrm{~V}\right.$ $\left.\mathrm{rms}, V_{L M A X}=112 \mathrm{~V} \mathrm{rms}\right)$.

5) Voltage booster operating frequency: $f=100 \mathrm{kHz},\left(f_{\min }\right.$ $=70 \mathrm{kHz}, f_{M A X}=130 \mathrm{kHz}$ ).

A lead-acid car battery operating voltage determines the ballast input voltage range.

2) Transient Specifications:

1) Output current: $2 \mathrm{~A}$ rms for $10 \mathrm{~s}$;

2) Output voltage: $0,5 \mathrm{kV}$ rms for $10-30 \mu \mathrm{s}$ (by using a voltage doubler, the ignitron input voltage is increased to $1 \mathrm{kV}$ and allows for a lamp break-over voltage of 25-30 $\mathrm{kV}$ to be achieved);

3) Output power: $70 \mathrm{~W}$ for $10 \mathrm{~s}$.

Moreover, the ballast circuit must allow for

1) an open-circuit operation with a high output voltage to provide a proper lamp break-over;

2) a fast transient response because of step variations of the load resistance;

3) a few seconds operation at an output power at least twice than the nominal power, and at an output current about five times higher than the nominal current.

\section{BALlast Circuit Operation AND DESIGN}

\section{A. Ballast Circuit Description}

A schematic circuit of the $35 \mathrm{~W}$ Automotive HID lamp is shown in Fig. 4(a) and the steady-state equivalent circuit is shown in Fig. 4(b). The ballast load is the series combination of lamp resistance $R_{L}=200 \Omega$ and ignitron inductance $L_{I}=$ $280 \mu \mathrm{H}$. The ignitron provided with the lamp is designed for a $400 \mathrm{~Hz}$ frequency and a minimum $1 \mathrm{kV}$ rms input voltage operation. Therefore, a $400 \mathrm{~Hz}$ square-wave inverter consisting of MOSFETs $M_{1}$ and $M_{2}$ and filter capacitor $C_{C}$ was utilized to drive the load. A half-wave peak rectifier constituted by diodes $D_{R 1}$ and $D_{R 2}$ and capacitors $C_{R 1}$ and $C_{R 2}$ shown in was the dc source of the $400 \mathrm{~Hz}$ inverter. A $100 \mathrm{kHz}$ operated

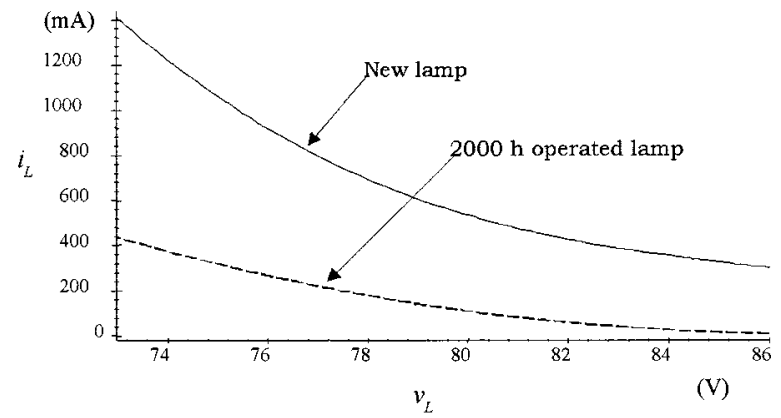

Fig. 2. Lamp current $i_{L}$ as a functions of voltage across the lamp electrodes $v_{L}$. Continuous line: new lamp. Dashed line: $2000 \mathrm{~h}$ operated lamp.

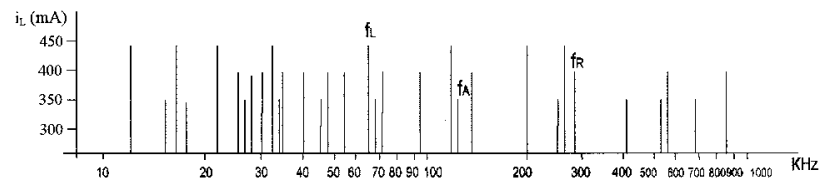

(a)

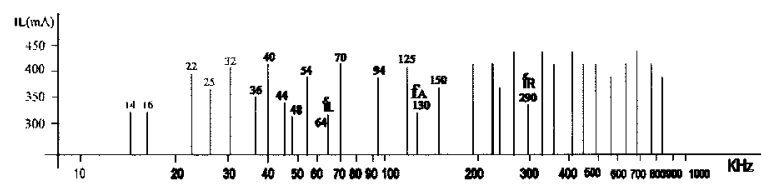

Fig. 3. Acoustic resonance frequencies in a $35 \mathrm{~W}$, automotive HID lamp. (a) Theoretically calculated. (b) Experimentally determined.

dc-ac class $\mathrm{E}$ inverter was utilized as a voltage booster to drive at a high frequency the rectifier. The ac-dc inductor $L_{i n}$, MOSFET $M_{3}$, dc-blocking capacitor $C_{S}$, series inductor $L_{S}$, a transformer with a turns ratio $n$, and resonant capacitor $C_{P}$ on the transformer secondary side constitute the $100 \mathrm{kHz}$ inverter. Capacitor $C_{S}$ removes the dc component from the inverter output current. Inductor $L_{S}$ and capacitor $C_{p}$ constitute the resonant parallel circuit.

A low value of the loaded resonant circuit quality factor $Q_{L}$ reduces the circulating currents in the inverter circuit. However, a low quality factor results in an inverter operation with a nearly sinusoidal output voltage where positive and negative half-waveforms are different. The half-wave rectifier shown in Fig. 4 ensures that a voltage with no dc component drives the lamp by charging capacitors $C_{R 1}$ and $C_{R 2}$ during the positive waveform. One terminal of the lamp-ignitron combination is connected to the common point of the center tapped transformer to achieve a lamp operation at zero dc current. The voltage doubler, constituted by diodes $D_{D 1}$ and $D_{D 2}$, capacitors $C_{D 1}$ and $C_{D 2}$, and resistor $R_{D 1}$ is included in the ballast circuit.

\section{B. Ballast Circuit Operation}

When the circuit is turned on the high-frequency ac-dc inverter is operated at no load and at a high quality factor of the resonant circuit. Consequently, the voltage across the transformer windings is high. The square-wave inverter is kept OFF, and the voltage doubler drives the ignitron. The ignitron capacitor $C_{I G}$ charges until its voltage is large enough to cause the gas discharge $G D_{I G}$ device turn on. The energy stored in capacitor 


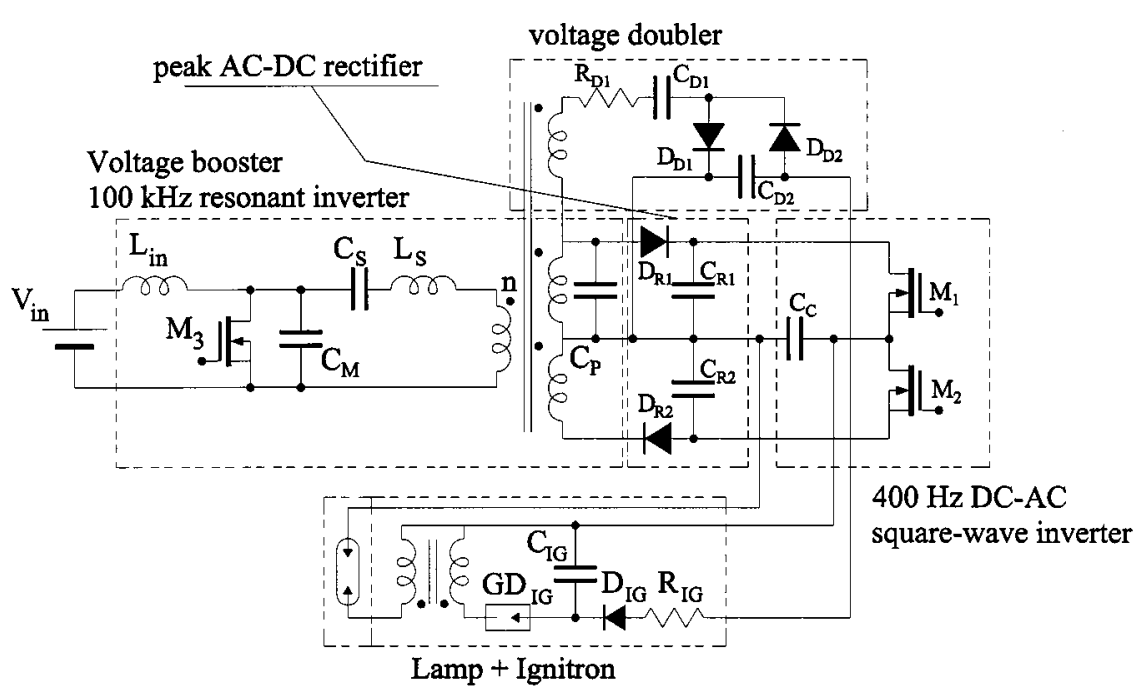

(a)

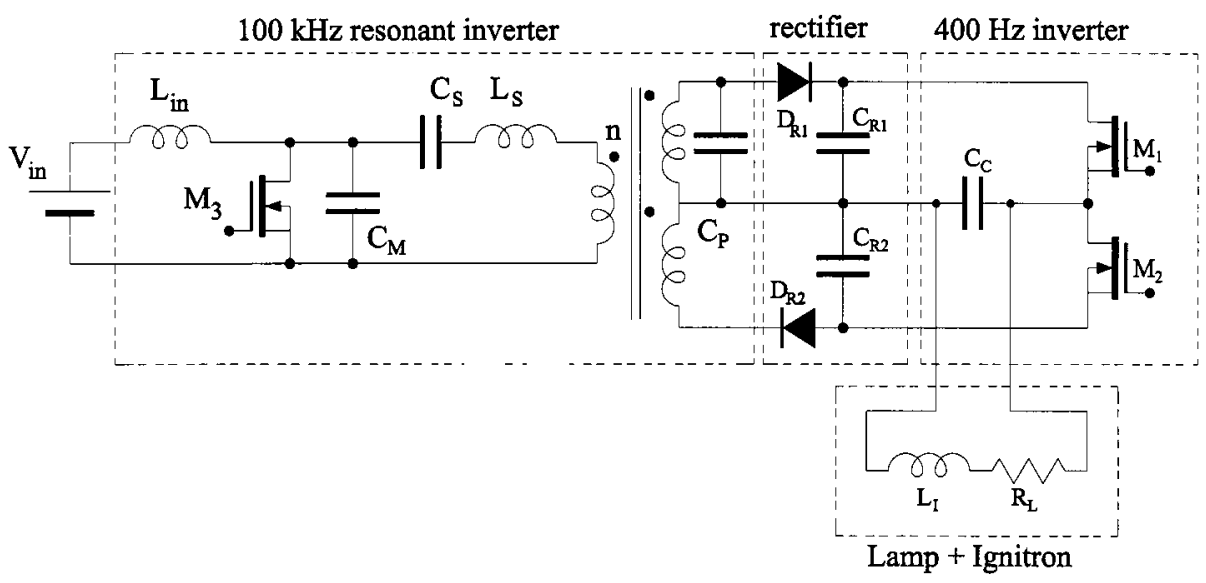

(b)

Fig. 4. Schematic circuit of the electronic circuit for automotive HID lamp ballast. (a) Overall power circuit of the ballast. (b) Ballast power circuit at the steady-state operation.

$C_{I G}$ is transferred to the lamp through the ignitron transformer and the lamp break-over is performed at $25-30 \mathrm{kV}$. During the warm-up time the ignitron is OFF, and the square-wave inverter is turned on. The lamp behaves as a low value resistance (nominal $R_{L}=18 \Omega$ ) and warm-up current (nominal $2 \mathrm{~A} \mathrm{rms)}$ is delivered to the lamp at a low voltage (nominal $35 \mathrm{~V} \mathrm{rms)}$ ). The steady-state operation voltage across the lamp and lamp resistance are increased to nominal values $V_{L}=85 \mathrm{~V} \mathrm{rms}$, and 200 $\Omega$, respectively, resulting in a nominal current $I_{L}=400 \mathrm{~mA}$ rms.

\section{Ballast Circuit Design}

The square-wave lamp voltage $v_{L}$ shown in Fig. 5 consists of a low-frequency nearly square-wave waveform with a superimposed sinusoidal waveform at a frequency ranging from $80 \mathrm{kHz}$ to $120 \mathrm{kHz}$. Since the sinusoidal waveform frequency is in the range of lamp acoustic resonance, its amplitude must be kept below $20 \%$ of the square-wave amplitude. From Fig. 4, the ballast circuit output capacitance is calculated as

$$
\begin{aligned}
C_{O} & =C_{R 1}+C_{C}=C_{R 2}+C_{C} \\
& =-\frac{1}{2 f_{\min } R_{L} \ln \left(1-\frac{\Delta V_{O}}{V_{O}}\right)}=160 \mathrm{nF}
\end{aligned}
$$

where it has been assumed that the capacitor discharging time is one half of the maximum switching period $T_{\max } / 2=1 / 2 f_{\min } \approx 7 \mu \mathrm{s}$ at a minimum operating frequency $f_{\min }=70 \mathrm{kHz}$, the lamp resistance is $R_{L}=200$ $\Omega$, and the maximum relative peak to peak voltage ripple is $\Delta V_{O} / V_{O}=0.2$.

The expression of the $100 \mathrm{kHz}$ inverter load impedance at the transformer secondary side is (3) and cannot be solved on a closed form. Therefore, the lamp resistance $R_{L}$ has been assumed to be the inverter load. Fig. 6(a) shows the class E inverter circuit loaded with a parallel resonant circuit where $R_{p 1}=$ $n^{2} R_{L}$ and $C_{P 1}=C_{P} / n^{2}$ are the lamp resistance and resonant 


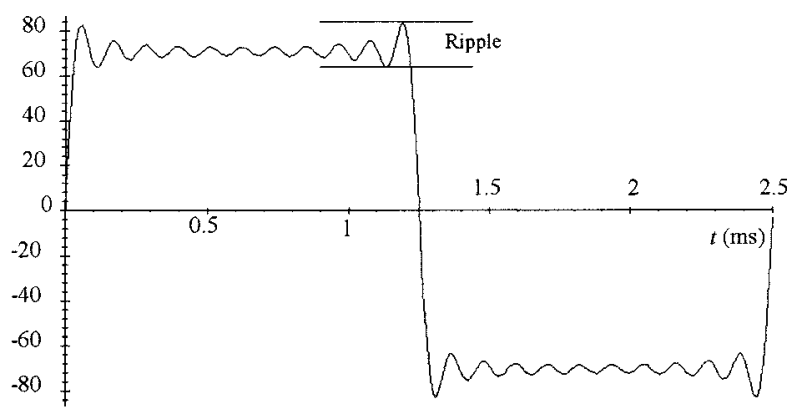

Fig. 5. Optimum ballast circuit steady state operation voltage waveform.

circuit parallel capacitance seen at the transformer primary side, respectively.

The voltage transfer function of the class $\mathrm{E}$ inverter including the loading parallel resonant circuit and the transformer is

$$
\begin{aligned}
M_{V} \equiv & \frac{V_{L}}{V_{i n}}=\frac{V_{S}}{V_{i n}} \frac{V_{T 1}}{V_{S}} \frac{V_{L}}{V_{T 1}} \\
= & \frac{1}{V_{i n}}\left(\frac{1}{2 \pi} \int_{0}^{2 \pi} v_{s}^{2}(\omega t) d \omega t\right)^{1 / 2} \\
& \cdot \frac{1}{\left\{\left[1-\left(\frac{f}{f_{O}}\right)^{2}\right]^{2} 1+\frac{1}{Q_{L}^{2}}\left(\frac{f}{f_{O}}\right)^{2}\right\}^{1 / 2} \frac{1}{n}}
\end{aligned}
$$

where $V_{i n}$ is the dc input voltage, $V_{S}$ is the rms voltage across the inverter MOSFET, $V_{T 1}$ is the transformer primary winding rms voltage, $V_{L}$ is the lamp rms voltage, $f_{O}=1 / 2 \pi \sqrt{L_{S} C_{P 1}}$ is the resonance frequency, $n=V_{T 1} / V_{L}$ is the transformer turns ratio, and $Q_{L}=n^{2} R_{L} /\left(2 \pi f_{O} L_{s}\right)=2 \pi f_{O} n^{2} R_{L} C_{P 1}$ is the parallel circuit loaded quality factor. Assuming $C_{S}>$ $10 C_{P 1}$, the overall capacitance of the parallel resonant circuit is $C_{T}=C_{S} C_{P 1} /\left(C_{S}+C_{P 1}\right) \approx C_{P 1}$. The rms voltage across the class $\mathrm{E}$ switch for a duty cycle $D=0.5$ is $V_{S} \approx 1.67 V_{\text {in }}$ [26]. Substitution of this into (4) gives

$$
M_{V} \approx \frac{1.67}{n\left\{\left[1-\left(\frac{f}{f_{O}}\right)^{2}\right]^{2} 1+\frac{1}{Q_{L}^{2}}\left(\frac{f}{f_{O}}\right)^{2}\right\}^{1 / 2} .}
$$

The steady state voltage transfer function at the minimum dc input voltage $M_{V}=85 / 9=9.5$ is achieved, for $Q_{L}=0.8, n=$ $1 / 8=0.125$, and for $f / f_{O}=1.25$, that is, $f_{O} \approx 80 \mathrm{kHz}$ at $f=$ $100 \mathrm{kHz}$. The series inductance is

$$
L_{S}=\frac{R_{L 1}}{2 \pi f_{O} Q_{L}}=\frac{n^{2} R_{L}}{2 \pi f_{O} Q_{L}}=8 \mu \mathrm{H}
$$

By connecting the parallel capacitor $C_{P}$ across the transformer secondary terminals the transformer leakage inductance is absorbed in the $8 \mu \mathrm{H}$ inductance. The resonant capacitance at the transformer primary side is given by

$$
C_{P 1}=\frac{C_{P}}{n^{2}}=\frac{1}{\left(2 \pi f_{O}\right)^{2} L_{S}}=495 \mathrm{nF} .
$$

This yields to a secondary side capacitance $C_{P}=$ $C_{P 1}(n / 2)^{2}=1.93 \mathrm{nF}$, whose reactance at an operating frequency $f=100 \mathrm{kHz}$ is $X_{C P 1}=1 / 2 \pi f C_{P 1}=3.22 \Omega$.
The equivalent series resistance and capacitance shown in Fig. 6(b) are calculated as

$$
R_{S E Q}=\frac{R_{L 1}}{1+\left(\frac{R_{L 1}}{X_{C P 1}}\right)^{2}}=\frac{n^{2} R_{L}}{1+\left(\frac{n^{2} R_{L}}{x_{C P 1}}\right)^{2}}=1.61 \Omega
$$

and

$$
C_{S E Q}=\frac{1+\left(\frac{X_{C P 1}}{R_{L 1}}\right)^{2}}{\omega X_{C P 1}}=\frac{1+\left(\frac{X_{C P 1}}{n^{2} R_{L}}\right)^{2}}{\omega X_{C P 1}}=1.02 \mu \mathrm{F}
$$

respectively. From (8) a reactance $X_{S E Q}=1 / \omega C_{S E Q}=$ $1.56 \Omega$ is calculated. Therefore, the resonant circuit acts as an impedance inverter allowing for a proper operation of the class E inverter close to the optimum operation [25]-[27].

The MOSFET parallel capacitance and the minimum input inductance are

$$
C_{<}=\frac{0.1836}{2 \pi f R_{S E Q}}=181 \mathrm{nF}
$$

and

$$
L_{I N \min }=2 *\left(\frac{\pi^{2}+4}{4}\right) * \frac{R_{S E Q}}{f}=7 \frac{R_{S E Q}}{f}=112 \mu \mathrm{H},
$$

respectively, [25] and [27].

The inverter MOSFET maximum voltage and current are $V_{S M}=3.562 V_{\text {inMAX }} \approx 57 \mathrm{~V}$ and $I_{S M}=2.862 I_{\text {inMAX }}=$ $13.25 \mathrm{~A}$. A $C_{S}=2 \mu \mathrm{F}$ has been assumed as the dc-blocking capacitor. Computer simulations demonstrated that the class $\mathrm{E}$ inverter MOSFET turns on at zero voltage, zero $d v / d t$, and low $d i / d t$ and turns off at low $d v / d t$ by increasing $L_{I N}$ and $C_{P}$ to $280 \mu \mathrm{H}$ and $2 \mathrm{nF}$, respectively, and decreasing $C_{M}$ to $143 \mathrm{nF}$.

\section{EXPERIMENTAL RESULTS}

A breadboard of the ballast circuit was assembled and tested by utilizing the currently available integrated circuit UC3843 to drive the IRFP150 MOSFET used as resonant inverter switch. The $400 \mathrm{~Hz}$ inverter was based on two IRF830 MOSFET's driven by an UC3825 with a TLP250 optocoupler utilized as MOSFET $M_{2}$ insulated gate drive circuit. The input inductance was assembled by winding 60 turns of $60 \times 0.1 \mathrm{~mm} \mathrm{Litz}$ wire on a E20 Siemens N87 ferrite core. The voltage booster transformer was built on a E25 Siemens N87 ferrite core. The primary side was wound with 10 turns of $60 \times 0.1 \mathrm{~mm} \mathrm{Litz}$ wire, the two secondary center tapped windings with 80 turns of $15 \times 0.1 \mathrm{Litz}$ wire, and the secondary winding driving the voltage doubler with 120 turns of $15 \times 0.1$ Litz wire.

The rms voltage measured at no load operation at the transformer secondary winding terminals ranged from $700 \mathrm{~V}$ to 800 $\mathrm{V}$ for a dc input voltage in the $9 \mathrm{~V}$ to $16 \mathrm{Vdc}$ range; the ignitron circuit input voltage was in the $1400 \div 1800 \mathrm{~V}$ range, which resulted in a $25 \mathrm{kV}$ voltage across the lamp. A $800 \mathrm{Vrms}$ secondary voltage was obtained with the voltage booster operated at a $72 \mathrm{kHz}$ frequency and a $65 \%$ duty cycle of MOSFET $M_{3}$.

The steady state lamp voltage $v_{L}$ waveform measured at $V_{I}=$ 12.5 Vdc and shown in Fig. 8 has a $85 \mathrm{~V}$ rms value, switches 


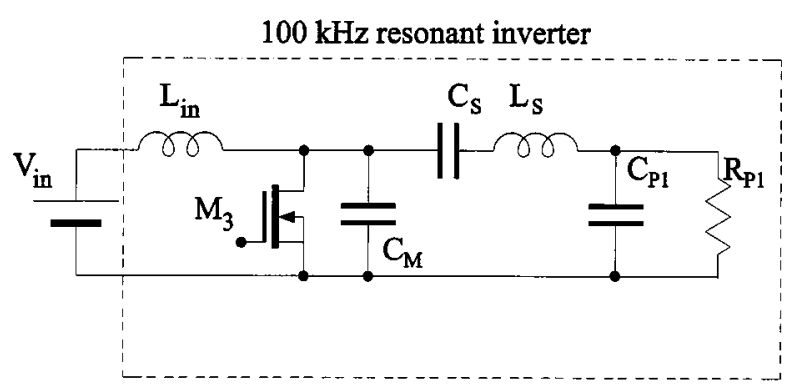

(a)

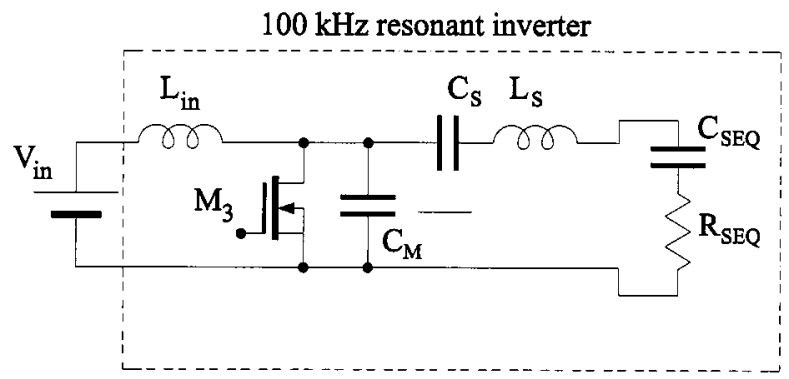

(b)

Fig. 6. Schematic circuit of the class $E$ inverter for the automotive HID lamp ballast. (a) Class $E$ inverter loaded by the parallel combination $C_{P 1}-R_{P 1}$. (b) Class $\mathrm{E}$ inverter loaded by the equivalent series circuit $C_{S E Q}-R_{S E Q}$.

Vertical: $50 \mathrm{~V} /$ div. Horizontal: $500 \mu \mathrm{s} /$ div.

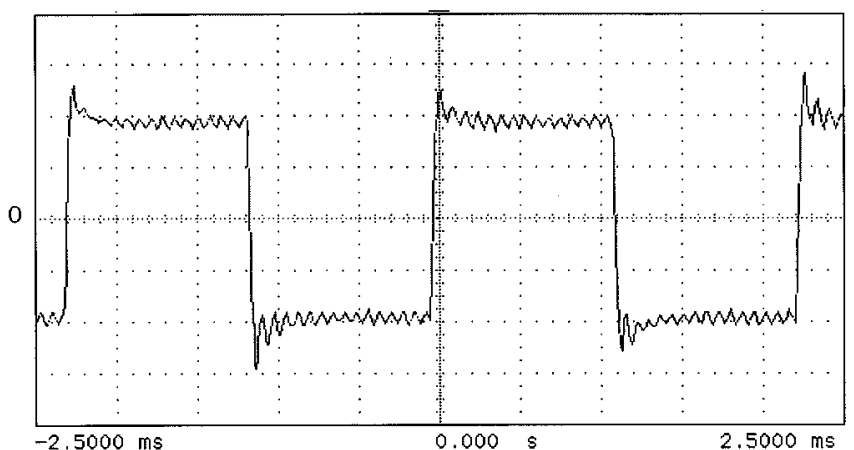

Fig. 7. Waveform of the lamp voltage $\mathrm{vL}$ at the steady state operation, an output power $P_{L}=35 \mathrm{~W}$, a voltage booster operating frequency $f_{V B}=110$ $\mathrm{kHz}$, and a dc input voltage $V_{I}=12.5 \mathrm{~V}$. Vertical: $50 \mathrm{~V} /$ div., horizontal: 500 $\mu \mathrm{s} / \mathrm{div}$.

from positive to negative values (and viceversa) at a limited $d v^{L} / d t$ and, therefore, satisfies the design requirements.

The lamp voltage waveform at the warm-up shown in Fig. 8 has a rms voltage $V_{L}=27 \mathrm{~V}$. The measured 0.8 relative ripple confirms validity of (2). During the warm-up time the lamp resistance is about $20 \Omega$, that is, one tenth of the steady state lamp resistance. This results in a resonant circuit higher quality factor and a lower resonance frequency than at the steady state operation. From (2), a relative voltage ripple $\Delta V_{O} / V_{O}=0.8$ is calculated for $f=97 \mathrm{kHz}, C_{O}=160 \mathrm{nF}$, and $R_{L}=20 \Omega$. During warm-up time, the low-frequency voltage component is much

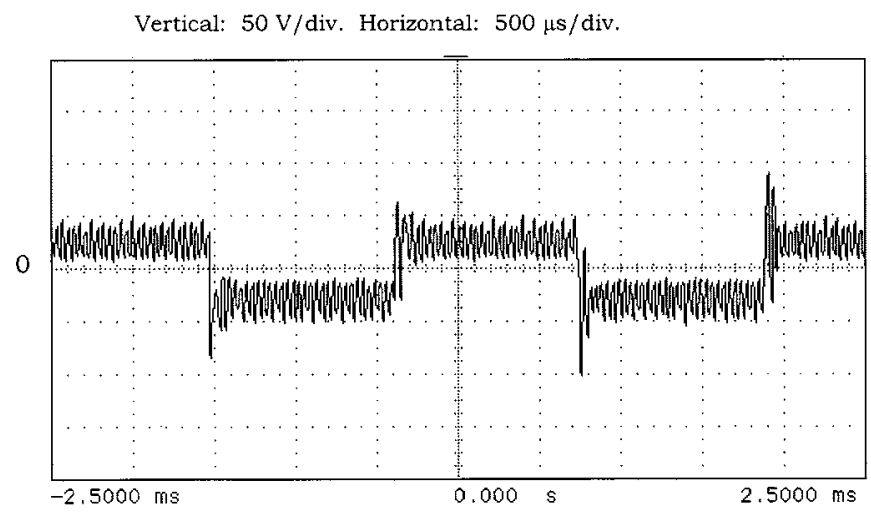

Fig. 8. Waveform of the lamp $\mu_{L}$ voltage at the warm-up operation, an output power $P_{L}=70 \mathrm{~W}$, a voltage booster operating frequency $f_{V B}=97 \mathrm{kHz}$, and a dc input voltage $V_{I}=12.5 \mathrm{~V}$. Vertical: $50 \mathrm{~V} /$ div., horizontal: $500 \mu \mathrm{s} / \mathrm{div}$.

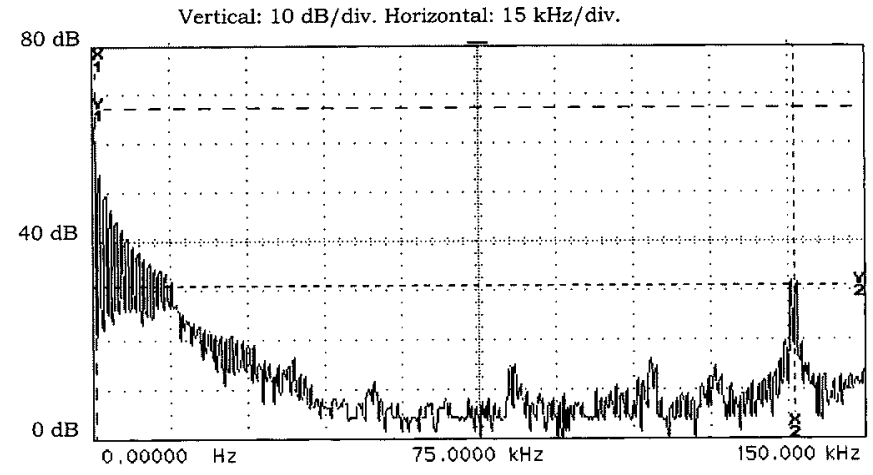

(a)

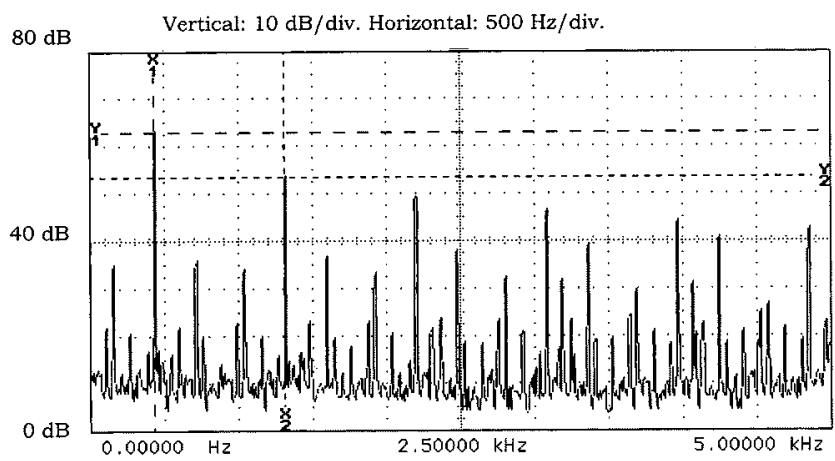

(b)

Fig. 9. Lamp voltage $v_{L}$ frequency domain representation at the steady operation, an output power $P_{L}=35 \mathrm{~W}$, a voltage booster operating frequency $f_{V B}=110 \mathrm{kHz}$, and a dc input voltage $V_{I}=12.5 \mathrm{~V}$. Vertical: (a) and (b) 10 $\mathrm{dB}$ V/div., horizontal: (a) $15 \mathrm{kHz} / \mathrm{div}$., (b) $500 \mathrm{~Hz} /$ div. (a) Voltage $V_{L}$ versus frequency for $0 \leq f \leq 150 \mathrm{kHz}$. (b) Detail of voltage $V_{L}$ versus frequency for a $0 \leq f \leq 5 \mathrm{kHz}$.

lower than the high frequency component and the lamp is operated at a high frequency. Experimental tests demonstrated that a high frequency operation results in a shorter warm-up time than a low frequency operation. The warm-up power delivered to the lamp was limited to $60 \mathrm{~W}$ at a $70 \%$ ballast circuit efficiency, which is relatively low. However, the ballast efficiency during 
this phase is not crucial because the warm-up lasts only a few seconds.

The measured steady state lamp voltage frequency spectrum shown in Fig. 9(a) demonstrates that a stable operation of the lamp is achieved because the square-waveform components have an amplitude lower than $30 \mathrm{~dB}$ at $f>30 \mathrm{kHz}$ and are nearly zero at frequencies higher than $45 \mathrm{kHz}$ up to $100 \mathrm{kHz}$. Morever, the amplitude of the $100 \mathrm{kHz}$ component is $36 \mathrm{~dB}$ lower than the $400 \mathrm{~Hz}$ component. The detail of the lamp voltage spectrum shown in Fig. 9(b) proves that the third order component energy is less than $20 \%$ of the energy delivered to the lamp by the $400 \mathrm{~Hz}$ component.

The steady state voltage and current waveforms of the MOSFET in the resonant inverter, at a $13 \mathrm{~V} \mathrm{dc}$ input voltage operation are shown in Fig. 10. The MOSFET is operated at a $37 \%$ duty cycle, a maximum drain-source reverse voltage $V_{S M}=70 \mathrm{~V}$, a maximum drain current $I_{S M}=6.3 \mathrm{~A}$, and a rms drain current $I_{D r m s}=3.56$ A. By assuming a MOSFET ON resistance $R_{D S O N}=55 \mathrm{~m} \Omega$, a $700 \mathrm{~mW}$ conduction loss is calculated ( $2 \%$ of the output power). Current and voltage waveforms shown in Fig. 10 demonstrate that the voltage booster MOSFET turns off at limited $d v / d t$ and turns on at zero voltage and at $d v / d t=0$. Actually, an efficiency $\eta=84 \%$ was achieved for the entire ballast circuit when operated at an input voltage $V_{i n}=12 \mathrm{~V}$. The converter efficiency kept nearly constant for a dc input voltage ranging from 12 to $16 \mathrm{~V}$ and maintained higher than $80 \%$ for $V_{i n}$ ranging from 9 to $12 \mathrm{~V}$.

\section{CONCLUSION}

An analysis and experimental verifications of a low-cost and high power-density ballast circuit for automotive HID lamp have been presented. Precise design criteria and specification have been derived. The ballast circuits is based on a $100 \mathrm{kHz}$ resonant inverter, a half-wave rectifier and a $400 \mathrm{~Hz}$ operated square-wave inverter.

The high-frequency resonant inverter contributes to the size and weigh reduction of the circuit inductors and transformer. The $400 \mathrm{~Hz}$ square-wave inverter prevents an inappropriate lamp operation due to the acoustic resonance and limits the electromagnetic noise radiated by the lamp. The nearly square-wave output voltage with a limited $d v / d t$ and zero dc component increases the lamp operating life.

A high efficiency operation and a high power-density circuit is achieved because the resonant inverter consists of only one switch, which turns on at zero voltage, zero $d v / d t$, and low $d i / d t$, and turns off at low $d v / d t$. Therefore, the converter operates at zero turn on losses, nearly zero turn off losses. The electronic ballast operates at a steady state efficiency $\eta=84 \%$ and allows for appropriate transient and steady state lamp operations.

The proposed circuit has a low component number and small volume but results in a larger number of components than other ballast circuit operated in megahertz range. This disadvantage is practically reduced by the low electromagnetic noise operation of the lamp achieved by the presented circuit.

It is recommended to study a ballast circuit driving the lamp with a low frequency, nearly sinusoidal lamp voltage. This
Vertical: voltage-upper trace $50 \mathrm{~V} /$ div., current-lower trace $10 \mathrm{~A} /$ div., Horizontal: $500 \mu \mathrm{s} /$ div.

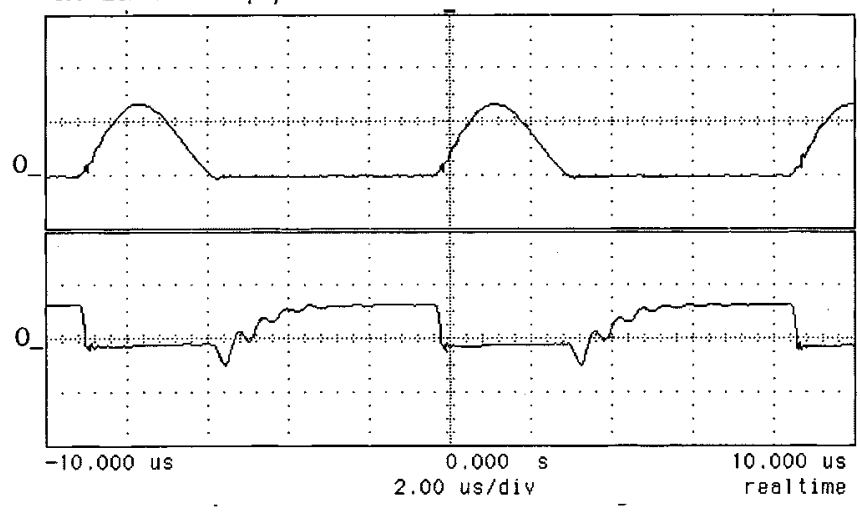

Fig. 10. Waveforms of the voltage booster MOSFET current and voltage at the steady operation, an output power $P_{L}=35 \mathrm{~W}$, a voltage booster operating frequency $f_{V B}=113.5 \mathrm{kHz}$, and a dc input voltage $V_{I}=13 \mathrm{~V}$. Vertical: upper $50 \mathrm{~V} /$ div., lower $10 \mathrm{~A} /$ div., horizontal: $2 \mu \mathrm{s} /$ div.

would contribute to increase the lamp life and reduces the electromagnetic noise generated by the lamp and the ballast.

\section{REFERENCES}

[1] H. H. Dahm, "New reflection-type headlamps using HID technology," in Automotive Design Advancements in Human Factors. Warrendale, PA: Society Automative Engineers, Inc., 1996, vol. SP 96/1155, pp. 153-156.

[2] S. Scwartz, W. Hendrischk, and J. Jiao, "Intellingent automotive lightinig," SAE Motor Vehicle Lighting, vol. PT-70, pp. 1-5, 1996.

[3] J. Neumann, "Improved projector headlamps using HID (litronic) and incandescent bulbs," SAE Motor Vehicle Lighting, vol. PT-70, pp. $15-22,1996$.

[4] J. Woerner and R. Neumann, "Motor vehicle lightning system with high intensity discharge lamps," SAE Motor Vehicle Lighting, vol. PT-70, pp. $41-48,1996$.

[5] J. H. Campbell, "Initial characteristics of high intensity discharge lamps on high frequency power," Illum. Eng., vol. 64, no. 12, p. 713, 1969.

[6] C. F. Scholz, "Characteristics of acoustical resonance in discharge lamps," Illum. Eng., vol. 65, no. 12, p. 713, 1970.

[7] H. L. Witting, "Acoustic resonances in cylindrical high-pressure arc discharges," J. Appl. Phys., vol. 49, no. 5, pp. 2680-2683, May 1978.

[8] J. W. Denneman, "Acoustic resonances in high-frequency operated low wattage metal halide lamps," Philips J. Res., vol. 38, pp. 263-272, Apr./May 1983.

[9] J. M. Davenport, "Direct current operation of low voltage metal halide lamps," Illum. Eng., vol. 14, no. 1, p. 274, 1984.

[10] Y. Kashimura, N. Aoike, H. Kobayashi, and O. Nomura, "Stable high frequency operation of high intensity discharge lamps and their ballast design," in Proc. 20th CIE, Amsterdam, The Netherlands, 1983.

[11] H. Nishimura, H. Nagase, K. Uchihashi, T. Shiomi, and M. Fukura, "A new electronic ballast for HID lamps," in Proc. 1987 IESNA Annu. Conf., Scottsdale, AZ, 1987.

[12] N. Fukimori, H. Nishimura, K. Uchihashi, and M. Fukura, "A study of HID lamp life when operated by electronic ballasts," J. Illum. Eng. Soc., vol. 49, pp. 41-47, Winter 1995.

[13] Y. Tsutomu, O. H. Masato, S. Toshihisa, K. Gunji, and K. Takeshi, "Characteristics of ballast for HID lamp with single-ended resonant-type inverter circuit using leakage inductance of transformer," in Proc. IEEE Int. Conf. Power Electron. Drive Syst., Piscataway, NJ, June 1995, pp. 246-250.

[14] J. M. Alonso, C. Blanco, E. Lopez, A. J. Calleja, and M. Rico, "Analysis, design, and optimization of the LCC resonant inverter as a high-intensity discharge lamp ballast," IEEE Trans. Power Electron., vol. PE-3, pp. 573-585, May 1988.

[15] M. Gulko, S. Ben-Yaakov, and A. Giter, "Current sorcing push pull parallel-resonance inverter (CS-PPRI): Theory and applications as a discharge lamp driver," IEEE Trans. Ind. Electron., vol. 41, pp. 285-291, June 1994. 
[16] S. Ben-Yaakov, M. Gulko, and A. Giter, "The simplest electronic ballast for HID lamps," IEEE Trans. Ind. Electron., pp. 634-640, Sept. 1996.

[17] C. Diazzi, F. Martignoni, P. Nora, R. Quagliino, and T. Placke, "A power BCD chipseet for automotive HID lamp ballast systems," in Proc. PESC '96, Baveno, Italy, June 1996, pp. 1766-1772.

[18] M. Gulko and S. Ben-Yaakov, "A Mhz electronic ballasts for automotive type HID lamps," in Proc. PESC '97, pp. 634-640.

[19] M. K. Kazimierczuk and W. Szaraniec, "Class D zero-voltage-switching inverter with only one shunt capacitor," in Proc. Inst. Elect. Eng., B, Electron. Power Applicat., vol. 139, Nov. 1992.

[20] ——, "Electronic ballast for fluorescent lamps," IEEE Trans. Power Electron., vol. 8, pp. 386-395, Oct. 1993.

[21] M. K. Kazimierczuk and S. Wang, "Frequency domain analysis of series converter for continuous conduction mode," IEEE Trans. Power Electron., vol. 7, pp. 270-279, Apr. 1992.

[22] M. K. Kazimierczuk, N. Thirunarayan, and S. Wang, "Analyis of series parallel resonant converters," IEEE Trans. Aerosp. Electron. Syst., vol. 29, no. 1, pp. 88-99, Jan. 1993.

[23] M. K. Kazimierczuk, W. Szaraniec, and S. Wang, "Analysis and design of parallel resonant converter at high Q," IEEE Trans. Aerosp. Electron. Syst., vol. 28, no. 1, pp. 35-50, Jan. 1992.

[24] M. K. Kazimierczuk and K. Puczko, "Power-output capability of class E amplifier at any loaded Q and switch duty cycle," IEEE Trans. Circuits Syst., vol. CAS-36, pp. 1142-1144, Aug. 1989.

[25] — "Impedance inverter for class E dc-dc converters," in Proc. 29th Midwest Symp. Circ. Syst., Lincoln, NE, Aug. 12, 1986, pp. 707-710.

[26] M. K. Kazimierczuk and D. Czarkowski, Resonant Power Converters. New York: Wiley, 1995.
[27] M. K. Kazimierczuk and X. T. Bui, "Class E dc/dc converter with a capacitive impedance inverter," IEEE Trans. Power Electron., vol. PE-4, pp. 124-135, Jan. 1989.

[28] A. Liberatore, M. Bartoli, A. Reatti, and M. K. Kazimierczuk, "Fullrange power supply based on a two-inductor resonant current-clamped (L $\left.{ }^{2} \mathrm{R}-\mathrm{CC}\right)$ DC-DC converter," in Proc. IEEE ISCAS '97, vol. 2, HongKong, June 11, 1997, pp. 873-876.

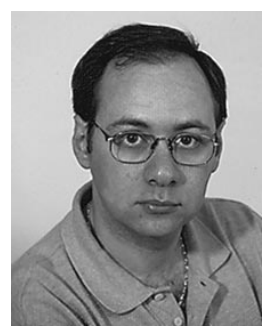

Alberto Reatti received the M.S. degree in electronic engineering and the Ph.D. degree from the University of Florence, Florence, Italy, in 1988 and 1993, respectively.

In 1992, he was an Associate Researcher with the Department of Electrical Engineering, Wright State University, Dayton, OH. In 1994, he was Visiting Professor with the Department of Electronics, University of Siena, Italy. He was a Visiting Professor with the Department of Electronics, University of Florence, for several years and is currently an Associate Researcher with the Department of Electronics, University of Florence. His research interests are in high-frequency high-efficiency power converters.

Dr. Reatti was Chairman of the Power Electronic and Power Systems Committee, IEEE ISCAS, in 1996 and 1997. 